\title{
Brucella endocarditis on double valvular prosthesis
}

\author{
R. LEZAUN* \\ M.D. \\ M. J. MAÎTRE \\ M.D.
}

J. TERUEL
M.D.

M. Artaza

M.D.

Clinica Puerta de Hierro, Servicio de Cardiología, Universidad Autónoma, Madrid 35

\begin{abstract}
Summary
The case is reported of a 48-year-old man suffering from Brucella endocarditis on a double prosthesis. The successful medical and surgical treatment is described. So far as the authors know, this is the first report of Brucella endocarditis from a heart valve prosthesis.
\end{abstract}

\section{Introduction}

Endocarditis following valvular prosthesis is a well known complication in heart surgery (Shafer and Hall, 1970; Arnet and Roberts, 1976).

An unusual species of Brucella (B. melitensis) was the cause of endocarditis following double prosthesis which is now described. The infection was successfully treated both medically and surgically.

A 48-year-old male presented in 1971 when catheterization led to a diagnosis of double aortic lesion and double mitral lesion. That same year a Bjork/Starr prosthesis was carried out. The postoperation clinical course was good until March 1976, when the patient became pyrexic and his general state was affected. Normal blood tests were negative and, because endocarditis was suspected, he was treated with benzylpenicillin $\left(5 \times 10^{6} \mathrm{u} . / 4 \mathrm{hr}\right)$ and streptomycin (one g/day) for 21 days at the end of which time he was discharged home without fever. He had not had any previous prophylaxis.

One month later he again became pyrexic and had petechiae. On auscultation, no murmurs were heard. Brucella agglutinations (titre 1/5120) showed positive. Blood cultures (Ruiz Casteñeda (1947) method) were positive to $B$. melitensis. Brucella endocarditis was thereby diagnosed and the patient was started on tetracycline $2 \mathrm{~g} /$ day and sulphadiazine $6 \mathrm{~g} /$ day for 3 courses of 21 days each. Shortly after beginning this treatment, the temperature returned to normal and the blood and marrow cultures were negative.

* Servicio de Cardiología, Hospital de Navarra, Pamplóna, Spain.

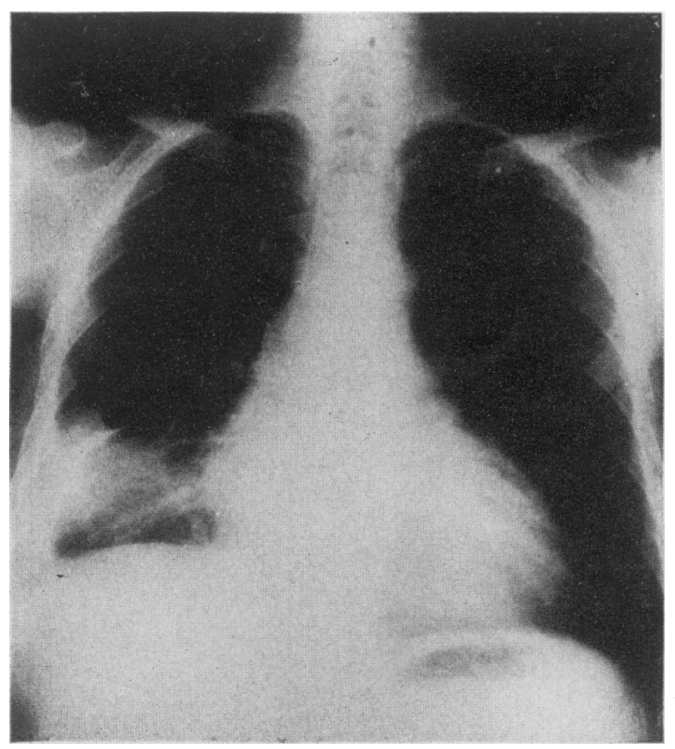

FIG. 1. X-ray after first operation showing a Bjork/Starr prosthesis.

At the end of the first course, the diastolic murmur of valvular dysfunction appeared at the left side of the sternum. From that moment, heart function deteriorated progressively; a severe leak through the catheterization of the aortic prosthesis was confirmed. Further surgery, to replace 2 new Bjork prostheses in the aortic and mitral positions, was carried out using Tycron sutures. Tests on the removed prostheses were negative. The post-operative course was uneventful and the patient was discharged 25 days later without sign of infection or of heart insufficiency. At 12 months later the patient remains asymptomatic.

\section{Discussion}

Endocarditis is an uncommon but serious complication of brucellosis (Spink and Nelson, 1939). 
The species most often implicated are $B$. melitensis and B. abortus (De La Chapelle, 1929; Bagley, Muller and Wells, 1936; Vittori et al., 1971). The most frequently affected valve is the aortic (Peery and Belter, 1960).

The present patient presented with endocarditis due to $B$. melitensis on a double valve prosthesis. The criteria on which diagnosis was based were: signs of prosthesis dysfunction and repeatedly positive blood and marrow cultures. Macroscopic anatomy tests during operation showed there was a leak from the prosthetic ring in the aortic position, and there were vegetations on both prostheses.

The formation of aneurysms in the sinuses of Valsalva, and dissecting aneurysms have been

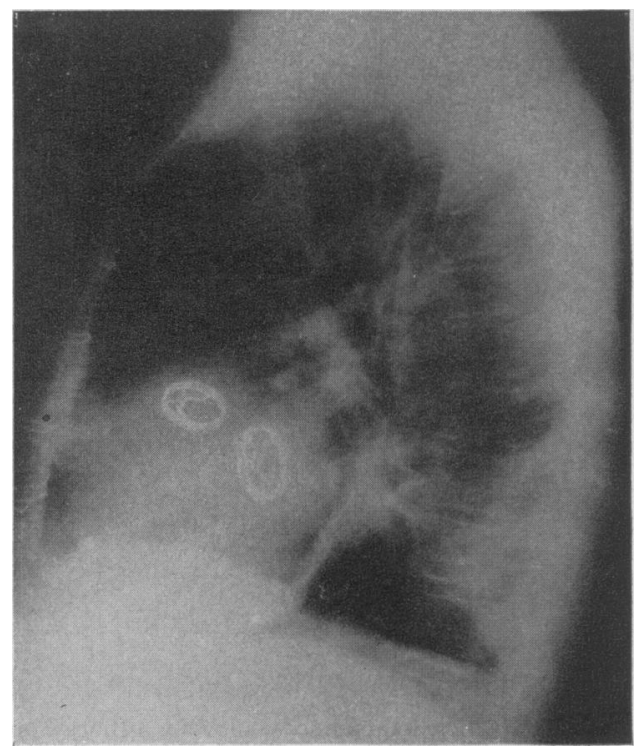

FIG. 2. X-ray after second operation showing a Bjork prosthesis in aortic and mitral position. described from cases of Brucella endocarditis (Grant, 1953; Dudley, Morgan and Lacey, 1951), but thereœ were no such lesions in the present case, neither were $\subseteq$ there such lesions as reported from an ECG of $\overrightarrow{\vec{*}}$ Brucella endocarditis reported by Dudley et al $\stackrel{\oplus}{-}$ (1951).

The patient was given 3 courses of tetracycline $\frac{\bar{\sigma}}{\bar{c}}$ and sulphadiazine and, although with the first $\overrightarrow{\widetilde{\sigma}}$ course blood and marrow cultures became negative, $\propto$ he was given 2 more courses to prevent a relapse leading to the characteristic chronic condition of $\vec{O}$ Brucella infection.

A second operation was necessary 3 months after $\vec{\omega}$ the first owing to the heart failure caused by a severe $\frac{\Omega}{O}$ leak of the prosthesis in the aortic position. The $\frac{0}{3}$ removed prostheses were tested routinely and with $\frac{3}{6}$. the Ruiz Casteñeda (1947) method with negative result.

The patient was discharged, with no symptoms, $\stackrel{N}{-}$ 25 days after surgery and remains asymptomatic $\overrightarrow{0}$ after one year's follow-up.

\section{References}

Arnet, E.N. \& Roberts, W.C. (1976) Prosthetic valve $\stackrel{\mathbb{D}}{\mathbb{D}}$ endocarditis. American Journal of Cardiology, 38, 281.

Bagley, V., Muller, S. \& Wells, A.H. (1936) Acuted brucellosis. Death from pulmonary embolism. Journal of the American Medical Association, 107, 1125.

De La Chapelle, C.E. (1929) Vegetative endocarditis due Brucella melitensis. American Heart Journal, 4, 732.

Dudley, F., Morgan, A. \& LACEY, B. (1951) Brucetal abortus endocarditis. British Medical Journal, 1, 1048.

Grant, G.H. (1953) Rupture of the heart as result of Brucella abortus endocarditis. British Medical Journal, 1, 914.

Peery, T.H. \& Belter, L.F. (1960) Brucellosis and heart disease. American Journal of Pathology, 36, 673.

Ruiz Casteñeda, M. (1947) Progresos Sociedad Experi-@ mental de Biologia Médica, 64, 114.

SPINK. W.N. \& Nelson, A.A. (1939) Brucella endocarditis. Annals of Internal Medicine, 13, 721.

ShAFER, R.B. \& HALL, W.H. (1970) Bacterial endocarditis following open heart surgery. American Journal of Cardio$\log y, 25,602$.

Vittori, F., Lachière-Ray, E., Garin, J.P. \& Pont, M 3 (1971) Endocardite brucellienne. A propos d'un cas. $\bar{\sigma}$ Presse Médicale, 79, 1391. 